\title{
PENDEKATAN BAYESIAN GELF UNTUK ESTIMASI PARAMETER MODEL SURVIVAL RAYLEIGH DENGAN PRIOR UNIFORM
}

\author{
Petty Jelda, Setyo Wira Rizki, Nurfitri Imro'ah \\ INTISARI
}

\begin{abstract}
Data survival adalah data yang menunjukkan waktu suatu individu atau objek yang dapat bertahan hidup hingga terjadinya suatu kegagalan atau kejadian tertentu. Tujuan dari penelitian ini adalah untuk menentukan model survival dan model hazard estimasi parameter berdistribusi Rayleigh dengan metode Bayesian General Entropy Loss Function (GELF) menggunakan prior Uniform. Estimasi parameter fungsi survival dan fungsi hazard Bayesian GELF didapat dengan mencari nilai estimasi parameter Bayesian GELF. Selanjutnya diterapkan pada data 175 pasien penderita Primary Billiary Cirrhosis $(P B C)$ yang diperoleh dari program $R$ versi 3.3 .0 untuk mengetahui peluang individu dapat bertahan hidup. Nilai estimasi parameter Bayesian GELF dari data yang dihitung menggunakan progam $R$ adalah 896,8008. Berdasarkan hasil estimasi parameter model survival distribusi Rayleigh metode Bayesian GELF dapat diketahui peluang seorang penderita penyakit PBC untuk bertahan hidup semakin lama semakin kecil (mendekati nol), dengan resiko kematian yang semakin besar.
\end{abstract}

Kata Kunci : Distribusi Rayleigh, Bayesian GELF, Prior Uniform.

\section{PENDAHULUAN}

Analisis survival dikembangkan pertama kali oleh Edmund Halley (1656-1742) di Inggris. Analisis ini menjadi salah satu alat penting dalam statistik dan ilmu aktuarial serta ilmu lainnya yang berhubungan dengan waktu. Sebagai contoh, ahli asuransi menggunakannya untuk menghitung uang yang harus dibayar peserta asuransi [1]. Tujuan dari analisis survival adalah untuk memodelkan distribusi yang mendasari objek waktu kegagalan dan untuk menilai ketergantungan dari waktu kegagalan pada objek yang diteliti.

Beberapa distribusi yang dapat digunakan untuk menggambarkan waktu tahan hidup antara lain distribusi Eksponensial, distribusi Weibull, distribusi Gamma, dan distribusi Rayleigh. Berdasarkan beberapa distribusi tersebut dipilih fungsi tahan hidup berdistribusi Rayleigh pada penelitian ini. Distribusi Rayleigh adalah kasus khusus dari distribusi parameter Weibull dua parameter [2]. Metode yang digunakan untuk mengestimasi parameter dalam analisis survival salah satunya yaitu metode Bayesian. Metode Bayesian memandang parameter sebagai variabel yang menggambarkan pengetahuan awal tentang parameter sebelum pengamatan dilakukan dan dinyatakan dalam suatu distribusi yang disebut prior [3]. Dalam penelitian ini prior yang digunakan adalah prior Uniform. Prior Uniform adalah prior yang paling sederhana dari semua distribusi probabilitas diskrit, dengan variabel acak yang mengasumsikan setiap nilainya dengan probabilitas sama [4]. Setelah pengamatan dilakukan, informasi dalam distribusi prior dikombinasikan dengan fungsi likelihood dan hasilnya dinyatakan dalam bentuk distribusi yang disebut distribusi posterior. Distribusi posterior selanjutnya menjadi dasar untuk inferensi di dalam metode Bayesian. Pendekatan dalam metode Bayesian yang digunakan dalam penelitian ini untuk mengestimasi parameter adalah GELF.

Tujuan dari penelitian ini adalah untuk menentukan estimasi parameter model survival dan model hazard berdistribusi Rayleigh dengan metode Bayesian GELF menggunakan prior Uniform. Kemudian menentukan nilai estimasi parameter Bayesian GELF pada data survival. Data yang digunakan adalah data survival 175 pasien penderita $\mathrm{PBC}$ yang diperoleh dari program R versi 3.3.0. Sirosis bilier primer atau primary biliary cirrhosis (PBC) adalah kondisi ketika saluran empedu di hati meradang dan tersumbat. Empedu adalah cairan yang diproduksi oleh hati. 
Langkah yang dilakukan pada metode Bayesian adalah menentukan fungsi likelihood dari fungsi kepadatan peluang dan fungsi survival. Setelah memperoleh fungsi likelihood dan distribusi prior, langkah berikutnya adalah merumuskannya ke dalam distribusi posterior. Setelah mendapatkan nilai distribusi posterior, dilakukan pendekatan Bayesian GELF untuk mencari nilai estimasi parameter Bayesian GELF, estimasi parameter fungsi survival Bayesian GELF dan estimasi parameter fungsi hazard Bayesian GELF. Kemudian diterapkan pada data, untuk menghitung nilai estimasi parameter model survival dan model hazard dari data tersebut.

\section{DISTRIBUSI WAKTU SURVIVAL}

Untuk estimasi waktu survival dari suatu individu dapat diperoleh dengan mengestimasi distribusi waktu survival. Distribusi waktu survival dapat dinyatakan dengan tiga fungsi yaitu fungsi kepadatan peluang, fungsi survival, dan fungsi hazard. Waktu survival $(T)$ merupakan variabel random nonnegatif yang mewakili waktu survival dari individu-individu dalam populasi yang merupakan variabel random kontinu dalam interval $[0, \infty)$ atau waktu survival pada waktu $t$ dengan $t>0$ [5]. Fungsi kepadatan peluang $f(t)$ didefinisikan sebagai turunan dari $F(t)$ sehingga:

$$
F(t)=P(T \leq t)=\int_{0}^{t} f(t) d t
$$

Fungsi survival $S(t)$ didefinisikan sebagai peluang suatu individu dapat bertahan hidup dengan waktu survival sampai dengan waktu $t$ dengan $t>0$ yaitu:

$$
S(t)=1-F(t)
$$

Fungsi hazard didefinisikan sebagai kelajuan suatu individu mati dalam interval waktu dari $t$ sampai $t+\Delta t$, jika diketahui individu tersebut masih dapat bertahan hidup sampai dengan waktu $t$. Fungsi hazard dinyatakan sebagai berikut:

$$
h(t)=\frac{f(t)}{S(t)}, \quad S(t)>0
$$

\section{DISTRIBUSI RAYLEIGH}

Pada distribusi Rayleigh $t$ adalah waktu survival dari variabel random kontinu $T$ yang mengikuti distribusi Rayleigh dengan parameter $\theta$, fungsi kepadatan peluang distribusi Rayleigh adalah:

$$
f(t)=\frac{t}{\theta^{2}} e^{-\frac{t^{2}}{2 \theta^{2}}}, \quad \theta>0
$$

Berdasarkan Persamaan (1) diperoleh fungsi distribusi kumulatif untuk distribusi Rayleigh yaitu:

$$
\begin{aligned}
F(t) & =\int_{0}^{t} f(t) d t \\
& =\int_{0}^{t} \frac{t}{\theta^{2}} e^{-\frac{t^{2}}{2 \theta^{2}}} d t \\
& =1-e^{-\frac{t^{2}}{2 \theta^{2}}}
\end{aligned}
$$


Sehingga fungsi survival dari distribusi Rayleigh adalah:

$$
\begin{aligned}
S(t) & =1-F(t) \\
& =1-\left(1-e^{-\frac{t^{2}}{2 \theta^{2}}}\right) \\
& =e^{-\frac{t^{2}}{2 \theta^{2}}}
\end{aligned}
$$

Berdasarkan Persamaan (4) dan (6) diperoleh fungsi hazard sebagai berikut:

$$
\begin{array}{rlrl}
h(t) & =\frac{f(t)}{S(t)} & \\
& =\frac{t}{\theta^{2}}, \quad \theta>0
\end{array}
$$

\section{FUNGSI GAMMA}

Salah satu manfaat penerapan penting dari fungsi gamma adalah untuk memudahkan menghitung integral tak wajar yang konvergen, yang tidak dapat secara langsung dihitung dari definisi, khususnya bilamana integral tak wajar tersebut melibatkan fungsi eksponensial negatif [6]. Fungsi gamma yang dinyatakan dengan $\Gamma(\alpha)$ sebagai berikut:

$$
\Gamma(\alpha)=\int_{0}^{\infty} x^{\alpha-1} e^{-x} d x, \text { yang konvergen untuk } \alpha>0
$$

\section{METODE BAYESIAN}

Metode Bayesian memandang parameter $\theta$ sebagai variabel random yang memiliki distribusi yang disebut distribusi prior. Dari distribusi prior digabungkan dengan fungsi likelihood maka dapat ditentukan distribusi posterior dan diperoleh estimasi parameter Bayesian. Jika $t_{1}, t_{2}, \ldots . t_{n}$ ditetapkan, maka fungsi likelihood dari parameter $\theta$ dinotasikan dengan $L\left(t_{i} ; \theta\right)$. Jika $T_{1}, T_{2}, \ldots T_{n}$ menyatakan sampel random dari $f\left(t_{i} ; \theta\right)$ maka [7]:

$$
\begin{aligned}
L\left(t_{i} ; \theta\right) & =f\left(t_{1} ; \theta\right) f\left(t_{2} ; \theta\right) \ldots . . f\left(t_{n} ; \theta\right) \\
& =\prod_{i=1}^{n} f\left(t_{i} ; \theta\right)
\end{aligned}
$$

Jika nilai $t$ adalah waktu hidup individu ke $i$ dengan $i=1,2, \ldots$, n sehingga fungsi likelihood dari distribusi Rayleigh adalah:

$$
L\left(t_{i} ; \theta\right)=\prod_{i=1}^{n}\left[\frac{t_{i}}{\theta^{2}}\right]\left[e^{-\frac{t^{2}}{2 \theta^{2}}}\right]
$$

Dalam metode Bayesian, ketika suatu populasi mengikuti distribusi tertentu dengan suatu parameter didalamnya (dalam hal ini $\theta$ ), maka parameter $\theta$ mengikuti suatu distribusi peluang yang disebut distribusi prior. Pada kasus ini distribusi prior yang digunakan adalah distribusi prior Uniform yang dinyatakan sebagai berikut: 


$$
f(\theta)=\frac{1}{b-a} \text { untuk } a<\theta<b \text { dan } f(\theta)=0 \text { untuk yang lain }
$$

Dengan $a=0$, maka $b$ adalah panjang interval. Serta nilai terbesar $t$ untuk $t>0$ digunakan sebagai model survival. Setelah informasi sampel diambil dan prior telah ditentukan maka distribusi posteriornya dicari dengan menggabungkan priornya dengan informasi sampel yang diperoleh dari fungsi likelihood [8]. Distribusi posterior dinyatakan sebagai berikut:

$$
f\left(\theta \mid t_{i}\right)=\frac{f(\theta) L\left(t_{i} ; \theta\right)}{\int_{0}^{\infty} f(\theta) L\left(t_{i} ; \theta\right) d \theta}, \quad \theta>0, t_{i}>0
$$

Dengan $f(\theta)$ merupakan distribusi prior dan $L\left(t_{i} ; \theta\right)$ merupakan fungsi likelihood. Berdasarkan Persamaan (9) dan (10) distribusi untuk posterior model survival berdistribusi Rayleigh dengan prior Uniform adalah:

$$
f\left(\theta \mid t_{i}\right)=\frac{\left(\frac{1}{\theta^{2 n}}\right)\left(e^{-\frac{\sum_{i=1}^{n} t_{i}^{2}}{2 \theta^{2}}}\right)}{-\left(\sum_{i=1}^{n} t_{i}^{2}\right)^{\frac{1}{2}-n}(2)^{n-\frac{3}{2}} \Gamma\left(n-\frac{1}{2}\right)}
$$

\section{ESTIMASI PARAMETER METODE BAYESIAN GELF}

Estimasi yang digunakan dalam kasus ini menggunakan General Entropy Loss Function atau biasa dikenal dengan GELF yang didefinisikan sebagai berikut [7]:

$$
L(\theta, \hat{\theta})=\left(\frac{\hat{\theta}}{\theta}\right)^{\alpha_{1}}-\alpha_{1} \ln \left(\frac{\hat{\theta}}{\theta}\right)-1, \quad \theta>0
$$

Untuk $\alpha_{1} \neq 0,0<\alpha_{1}<\infty$ dengan $\alpha_{1}$ menunjukkan penyimpangan asimetri dan $\hat{\theta}$ merupakan estimator Bayesian untuk $\theta$ dengan pendekatan GELF. Estimasi Bayesian GELF dari $\hat{\theta}$ diperoleh dengan meminimumkan ekspektasi GELF yang diperoleh sebagai berikut:

$$
\begin{aligned}
& \frac{d[E(L(\theta, \hat{\theta}))]}{d \hat{\theta}}=0 \\
& E\left[\frac{d}{d \hat{\theta}}\left[\left(\frac{\hat{\theta}}{\theta}\right)^{\alpha_{1}}-\alpha_{1} \ln \left(\frac{\hat{\theta}}{\theta}\right)-1\right]\right]=0
\end{aligned}
$$




$$
\begin{aligned}
& E\left[\left(\alpha_{1} \theta^{-\alpha_{1}} \hat{\theta}^{\alpha_{1}-1}\right)-\alpha_{1}\left(\frac{1}{\hat{\theta}}\right)\right]=0 \\
& \alpha_{1} \hat{\theta}^{\alpha_{1}-1} E\left[\theta^{\alpha_{1}}\right]=\frac{\alpha_{1}}{\hat{\theta}} \\
& \hat{\theta}=\left[E\left(\theta^{-\alpha_{1}}\right)\right]^{-\frac{1}{\alpha_{1}}}
\end{aligned}
$$

Berdasarkan Persamaan (15) maka estimasi parameter dengan metode Bayesian GELF berdistribusi Rayleigh menggunakan prior Uniform adalah:

$$
\begin{aligned}
\hat{\theta_{B G}} & =\left[\frac{\Gamma\left(n+\frac{\alpha_{1}}{2}-\frac{1}{2}\right)\left(\sum_{i=1}^{n} t_{i}^{2}\right)^{-\frac{\alpha_{1}}{2}}\left(2^{\frac{\alpha_{1}}{2}}\right)}{\Gamma\left(n-\frac{1}{2}\right)}\right]^{\frac{-1}{\alpha_{1}}} \\
& =\left[\frac{\Gamma\left(n+\frac{\alpha_{1}}{2}-\frac{1}{2}\right)}{\Gamma\left(n-\frac{1}{2}\right)}\right]^{\frac{-1}{\alpha_{1}}}\left(\sum_{i=1}^{n} t_{i}^{2}\right)^{\frac{1}{2}}(2)^{-\frac{1}{2}}
\end{aligned}
$$

Bedasarkan Persamaan (16) maka estimasi fungsi survival dan fungsi hazard dengan metode Bayesian GELF berdistribusi Rayleigh menggunakan prior Uniform adalah:

$$
\hat{S_{B G}\left(t_{i}\right)=e^{-\frac{t^{2}}{\left.\left[\frac{\Gamma\left(n+\frac{\alpha_{1}}{2}-\frac{1}{2}\right)}{\Gamma\left(n-\frac{1}{2}\right)}\right]^{\frac{-1}{\alpha_{1}}}\left(\sum_{i=1}^{n} t_{i}^{2}\right)^{\frac{1}{2}}(2)^{-\frac{1}{2}}\right]^{2}}}}
$$

$$
\hat{h_{B G}}\left(t_{i}\right)=\frac{t_{i}}{\left[\left[\frac{\Gamma\left(n+\frac{\alpha_{1}}{2}-\frac{1}{2}\right)}{\Gamma\left(n-\frac{1}{2}\right)}\right]^{\frac{-1}{\alpha_{1}}}\left(\sum_{i=1}^{n} t_{i}^{2}\right)^{\frac{1}{2}}(2)^{-\frac{1}{2}}\right]^{2}}
$$




$$
\hat{h_{B G}}\left(t_{i}\right)=\frac{2 t_{i}}{\left[\frac{\Gamma\left(n+\frac{\alpha_{1}}{2}-\frac{1}{2}\right)}{\Gamma\left(n-\frac{1}{2}\right)}\right]^{\frac{-2}{\alpha_{1}}}\left(\sum_{i=1}^{n} t_{i}^{2}\right)}
$$

\section{STUDI KASUS}

Data yang digunakan adalah menggunakan data survival 175 pasien penderita PBC. Hipotesis untuk distribusi data pada penelitian ini:

$H_{0}$ : Data mengikuti distribusi Rayleigh

$H_{1}$ : Data tidak mengikuti distribusi Rayleigh

Nilai $\alpha=5 \%=0,05$ digunakan dalam menentukan keputusan akhir untuk menerima atau menolak $H_{0}$. Nilai $p$-value pada uji distribusi Rayleigh ialah 0,09991, artinya $p$-value $>0,05$ maka $H_{0}$ diterima dan data berdistribusi Rayleigh. Berdasarkan Persamaan (12) dengan menggunakan program R di dapat nilai $\hat{\theta}_{B G}=896,8008$. Sehingga jika diambil sembarang nilai $t_{i}$ pada data penderita PBC dengan $t_{1}=41, t_{45}=625, t_{88}=999, t_{132}=1504, t_{175}=2400$ maka dapat diketahui nilai survival dan nilai hazard dari waktu tersebut yang dapat dilihat pada Tabel 1 berikut:

\section{Tabel 1 Hasil Estimasi Parameter Fungsi Survival dan Fungsi Hazard Distribusi Rayleigh dengan Metode Bayesian GELF}

\begin{tabular}{|c|c|c|c|}
\hline No & Waktu & Survival BG $\left(\hat{S}_{B G}\right)$ & Hazard BG $\left(\hat{h}_{B G}\right)$ \\
\hline 1 & 41 & 0,99895548 & $5,097906 \times 10^{-5}$ \\
\hline 2 & 625 & 0,78438920 & $7,771199 \times 10^{-4}$ \\
\hline 3 & 999 & 0,53770074 & $1,242148 \times 10^{-3}$ \\
\hline 4 & 1.504 & 0,24505170 & $1,870061 \times 10^{-3}$ \\
\hline 5 & 2.400 & 0,02784872 & $2,984140 \times 10^{-3}$ \\
\hline
\end{tabular}

Tabel 1 menunjukkan hasil estimasi parameter fungsi survival dan fungsi hazard distribusi Rayleigh metode GELF pada kasus penderita PBC. Maka jika seorang individu mengidap penyakit PBC selama 41 hari peluang individu untuk bertahan hidup adalah 0,99895548 dan probabilitas kematiannya adalah 5,097906 $\times 10^{-5}$, selama 788 hari peluang individu untuk bertahan hidup adalah 0,67974447 dan probabilitas kematiannya adalah 7,771199 $\times 10^{-4}$, selama 1153 hari peluang individu untuk bertahan hidup adalah 0,43758333 dan probabilitas kematiannya adalah $1,242148 \times$ $10^{-3}$, selama 1576 hari peluang individu untuk bertahan hidup adalah 0,21349255 dan probabilitas kematiannya adalah $1,870061 \times 10^{-3}$, dan selama 2400 hari peluang individu untuk bertahan hidup adalah 0,02784872 dan probabilitas kematiannya adalah $2,984140 \times 10^{-3}$. 
Berdasarkan Tabel 1, diperoleh grafik fungsi survival dan fungsi hazard sebagi berikut:

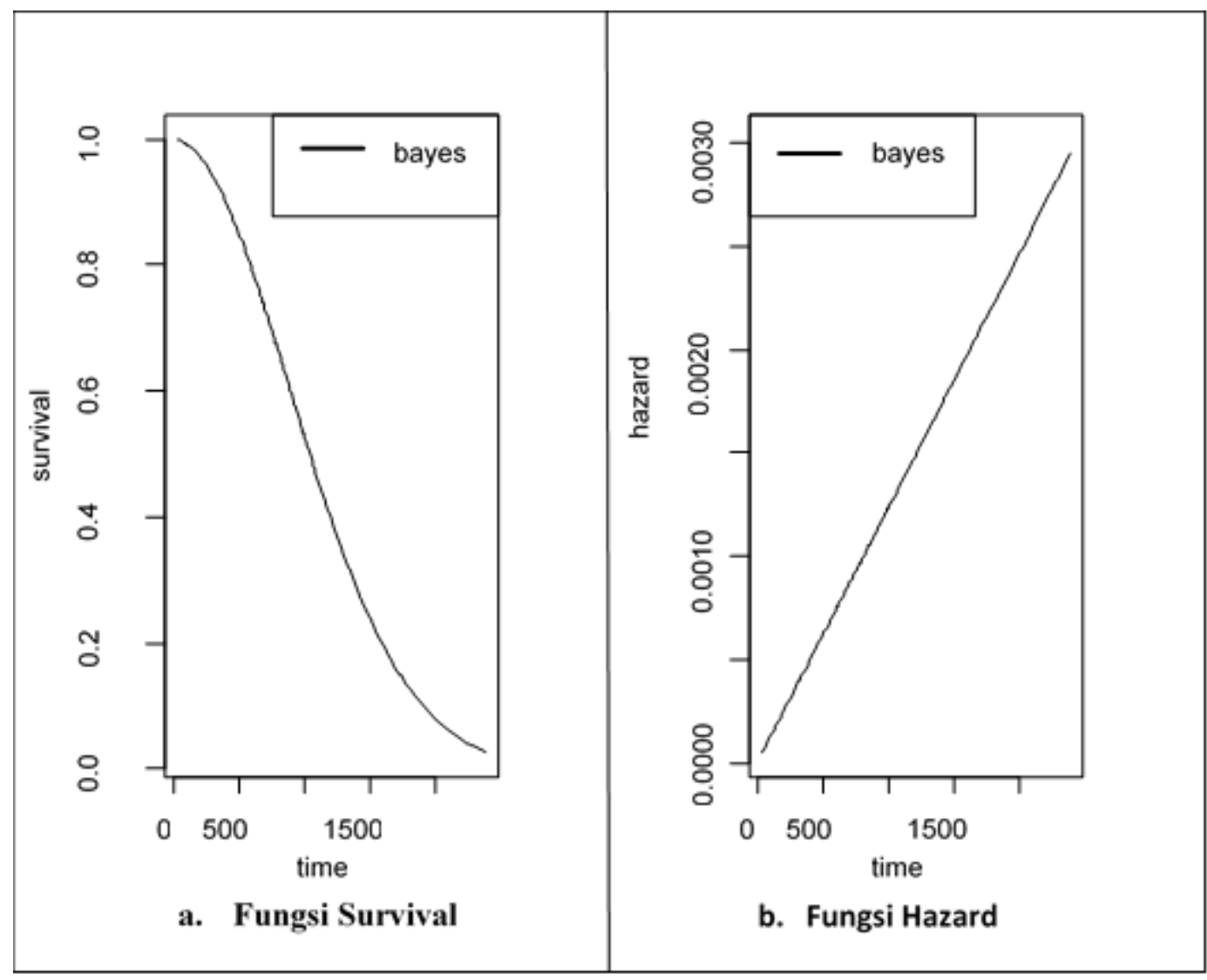

\section{Gambar 1 Grafik Fungsi Survival dan Fungsi Hazard Distribusi Rayleigh dengan Metode Bayesian GELF}

Gambar 1a menunjukkan fungsi survival, jika semakin lama individu menderita penyakit PBC maka semakin kecil peluang untuk individu dapat bertahan hidup. Sedangkan Gambar 1b menunjukkan fungsi hazard, jika semakin lama individu menderita penyakit PBC maka semakin besar nilai probabilitas kematian individu tersebut.

\section{PENUTUP}

Berdasarkan data yang digunakan pada penelitian ini yaitu data penderita penyakit PBC, dengan menggunakan program $\mathrm{R}$ didapat nilai $\hat{\theta}_{B G}=896,8008$. Berdasarkan hasil estimasi parameter model survival distribusi Rayleigh metode Bayesian GELF dapat diketahui peluang seorang individu dapat bertahan hidup pada kasus penderita PBC jika mengidap penyakit selama 41 hari adalah 0,99895548, selama 625 hari adalah 0,78438920, selama 999 hari adalah 0,53770074, selama 1504 hari adalah 0,24505170, dan selama 2400 hari adalah 0,02784872. Sehingga hasil estimasi parameter model survival distribusi Rayleigh metode Bayesian GELF dapat diketahui peluang seorang penderita penyakit PBC untuk bertahan hidup semakin lama semakin kecil (mendekati nol), dengan resiko kematian yang semakin besar.

\section{DAFTAR PUSTAKA}

[1] Gayatri, D., \& Halley, E. Mengenal Analisis Ketahanan ( Survival Analisis ).2005; 9(1):36-40.

[2] Boudjerda, Chadli, Merradja, \& Fellag. Bayesian Estimation of the Rayleigh distribution 
under different loss function, 2017;4.doi.org/10,1285/i20705948v10n1p50

[3] Bolstad, \& William.M. Introduction to Bayesian Statistics. (U. of Waikato, Ed.) (second). Hamilton,New Zealand; 2007 :Wiley Series In Probability and Statics

[4] Walpole, R., H.Myers, R., L.Myers, S., \& Ye, K. Probability \& Statistics for Engineers \&; Scientists. (T. Benfatti, Ed.) (eighth). London; 2007 :Pearson Education International.

[5] Lawless, J.F. Statistical Models and Method for Lifetime Data Second Edition, John Wiley \& Sons Inc, New York; 2003.

[6] Prayudi. Kalkulus Lanjut Fungsi Banyak Variabel dan Penerapannya. Yogyakarta; 2008: Graha Ilmu.

[7] Bickel, P. J., Diggle, P., Fienberg, S., Gather, U., Olkin, I., Zeger, S., Demography, S. Springer Series in Statistics Springer Series in Statistics. (J. G.Ibrahim, Ed.) (second). Boston,Amerika; 2010: Springer. doi.org/10,1007/978-0-387-98135-2

[8] Guure, C.B., and Ibrahim, N.A., Bayesian Analysis of the Survival Function and Failure Rate of Weibull Distribusion with Cencored Data. Journal Mathematical Problems in Engineering, Vol 2012, Article ID 329489, 2012.

\footnotetext{
PETTY JELDA $\quad$ : Jurusan Matematika FMIPA UNTAN Pontianak, peti.peti.mi5a@gmail.com

SETYO WIRA RIZKI : Jurusan Matematika FMIPA UNTAN Pontianak, setyo.wirarizki@math.untan.ac.id

NURFITRI IMRO'AH : Jurusan Matematika FMIPA UNTAN Pontianak, nurfitriimroah@math.untan.ac.id
} 